\title{
OPTIMALISASI FUNGSI MASJID UNTUK KEAKTIFAN MAHASISWA
}

\author{
Siskandar ${ }^{1}$ \\ Institut PTIQ Jakarta \\ Email: siskandar2000@yahoo.com \\ Ahmad Yani ${ }^{2}$ \\ Institut PTIQ Jakarta \\ Email: ahmadyaniaqiilah@gmail.com
}

\begin{abstract}
This research aims to analyze the function of the Kemanggisan at-Taqwa Mosque and campus mosques in terms of Worship, Education, Missionary Endeavor, Economy, Social Community, Politics, Health, Technology, Islamic Brotherhood, and Cadreization. Other objectives are the optimization of the function of the Kemanggisan at-Taqwa Mosque and several campus mosques, the transformation of mosque programs towards student activities and discovering the concept of mosque programs that are relevant to student activities.

The mosque that was made the object of observation was the at-Taqwa mosque of the West Jakarta Kemanggisan Tax Complex with the consideration that the mosque is a central mosque that cooperates with 116 mosques in West Jakarta and close to 5 universities, namely: Trisakti University, Tarumanagara University, Esa Unggul University, Bina Nusantara University, and Mercu Buana University. This research period lasts from January 2019 - August 2019.

This research uses a qualitative approach which is a study that uses an approach to find a deepening of symptoms that have specific substance which in this case pertains to student activities in the mosque. These findings will be analyzed using existing theories.

The results of the research analysis showed that the role of students in the prosperity of the at-Taqwa mosque showed a declining trend in terms of quantity and quality and some campus mosque programs were not optimal. The author found several concept programs for students to further optimize the function of the mosque in the fields of worship, education, missionary
\end{abstract}


Optimalisasi Fungsi Masjid Untuk.. I

endeavor, economics, social, political, technology, health, Islamic brotherhood and regeneration.

Keywords: Optimization of Function, Mosque, University Student. 


\section{ABSTRACT}

Penelitian ini bertujuan untuk menganalisis fungsi masjid at-Taqwa Kemanggisan dan masjid-masjid kampus dari segi Ibadah, Pendidikan, Dakwah, Ekonomi, Sosial Kemasyarakatan, Politik, Kesehatan, Teknologi, Ukhuwah Islamiyah, dan Kaderisasi. Tujuan lain adalah optimalisasi fungsi Masjid atTaqwa Kemanggisan dan beberapa masjid kampus, transformasi program masjid terhadap aktivitas mahasiswa dan menemukan konsep program masjid yang relevan dengan aktivitas mahasiswa.

Masjid yang dijadikan obyek pengamatan adalah masjid at-Taqwa Kompleks Pajak Kemanggisan Jakarta Barat dengan pertimbangan bahwa masjid tersebut merupakan masjid sentral yang bekerja sama 116 masjid di Jakarta Barat dan dekat dengan 5 Universitas, yaitu: Universitas Trisakti, Universitas Tarumanagara, Universitas Esa Unggul, Universitas Bina Nusantara, dan Universitas Mercu Buana. Periode penelitian ini berlangsung dari bulan Mei 2017 - Oktober 2019.

Penelitian ini menggunakan pendekatan kualitatif yaitu penelitian yang menggunakan cara pendekatan untuk menemukan pendalaman tentang gejala yang memiliki substansi khusus yang dalam hal ini megenai aktifitas mahasiswa di masjid. Temuan-temuan tersebut nantinya akan dianalisis dengan menggunakan teori yang sudah ada.

Hasil dari analisis penelitian menunjukkan bahwa peranan mahasiswa dalam memakmurkan masjid at-Taqwa menunjukan kecenderungan yang menurun dari segi kuantitas dan kualitas dan beberapa program masjid kampus yang belum optimal. Penulis menemukan beberapa konsep program untuk mahasiswa agar lebih mengoptimalkan fungsi masjid dalam bidang ibadah, pendidikan, dakwah, ekonomi, sosial kemasyarakatan, politik, kesehatan, teknologi, ukhuwah Islamiyah dan kaderisasi.

Kata Kunci: Optimalisasi Fungsi, Masjid, Mahasiswa 


\section{Pendahuluan}

Masjid adalah suatu tempat (bangunan) yang fungsi utamanya sebagai tempat untuk menyembah Allah SWT. Di samping sebagai tempat beribadah dalam arti khusus (mahdhah), masjid juga merupakan tempat beribadah secara luas (ghairu mahdhah) selama dilakukan dalam batas-batas syari'ah. Masjid bukan hanya untuk melaksanakan shalat, tetapi juga sebagai sekolahan, balai pertemuan dan tempat untuk mempersatukan berbagai elemen masyarakat. Masjid juga tempat untuk mengatur urusan, bermusyawarah dan menjalankan roda pemerintahan. Masjid besar, bersih, dan indah merupakan dambaan, namun ini belum cukup apabila tidak ditunjang dengan aktivitas untuk memakmurkan masjid. Masjid menjadi pilar spiritual penyangga kehidupan duniawi umat dan sebagai indikator kesejahteraan umat lahir dan batin. Apabila tidak ada masjid di wilayah yang berpenduduk mayoritas agama Islam atau ada masjid tetapi tidak digunakan sebagai pusat aktivitas kehidupan umat, maka belum bisa dikatakan dapat memberikan kontribusi terhadap kesejahteraan rakyat sekitarnya, bahkan merupakan isyarat negatif berupa disorientasi kehidupan umat. ${ }^{1} \quad$ Dalam dua situasi dimana tidak ada masjid atau ada masjid namun belum dioptimalkan fungsi masjid sebagaimana mestinya, maka umat akan mengalami kebingungan dan menderita berbagai penyakit fisik maupun mental serta tidak dapat menikmati distribusi aliran ridha dan energi dari Allah SWT. $^{2}$

Terdapat tiga istilah yang berkaitan dengan kepengurusan masjid, yaitu: ${ }^{3}$

1. Ri'ayah masjid, yaitu kegiatan pemeliharaan fisik bangunan masjid.

2. Idarah masjid atau manajemen masjid.

3. Ta'mir masjid, yaitu kegiatan memakmurkan masjid.

\footnotetext{
${ }^{1}$ Sidi Gazalba, Masjid Pusat Ibadat dan Kebudayaan Islam, Jakarta: Pustaka Antara, 1971, hal. 27.

${ }^{2}$ Nana Rukmana DW, Masjid dan Dakwah, Merencanakan, Membangun dan Mengelola Masjid, Mengemas Substansi Dakwah, Upaya Pemecahan Krisis Moral dan Spritual, Jakarta: Almawardi Prima, 2002, hal. 76. Bandingkan juga dalam M Quraish Shihab, Wawasan alQur'an, Tafsir Maudhu'i atas pelbagai persoalan umat, Bandung: Mizan, 1996, hal. 204.

${ }^{3}$ Sofyan Syafri Harahab, Pedoman Manajemen Masjid, Jakarta: PT Pustaka Quantum Prima, 2001, hal. 4.
} 
Fungsi pokok masjid adalah sebagai tempat beribadah dan bermuamalah yang dibangun atas dasar taqwa dan tauhid, bertujuan semata-mata untuk mencari ridha Allah.

Berdasarkan latar belakang di atas, dan dilihat dari fenomena yang terjadi maka permasalahan yang akan dibahas adalah:

1. Jumlah mahasiswa yang aktif dalam kepengurusan di masjid at-Taqwa cenderung mengalami penurunan. ${ }^{4}$

2. Aktivitas remaja masjid kurang mendapat perhatian dalam kepengurusan masjid.

3. Aktivitas yang melibatkan kepemudaan mulai mengalami kemunduran dalam hal kualitas.

4. Kaderisasi kepemudaan tidak berjalan dengan baik.

5. Kajian tematik mengenai generasi muda kurang mendapat perhatian.

6. Terjadi overlapping dalam kepanitiaan programprogram tertentu karena kurangnya peran pemuda atau mahasiswa.

7. Remaja masjid at-Taqwa (RISMATA) yang sudah berkembang dengan baik mengalami kemerosotan dalam program kepemudaan dan aktivitas sosial kemasyarakatan.

8. Aktivitas rutin dari JPRMI atau Jaringan Pemuda dan Remaja Masjid Indonesia di masjid at-Taqwa mulai berkurang frekuensinya.

Pada Penelitian ini, peneliti akan melakukan penelitian pada masjid at-Taqwa yang terletak di Kompleks Pajak Kemanggisan Jakarta Barat, Kampus Universitas Trisakti, Kampus Universitas Tarumanagara, Kampus Universitas Esa Unggul, Kampus Universitas Bina Nusantara, dan Kampus Universitas Mercu Buana.

Dari penelitian tersebut diharapkan dapat merumuskan masalah yaitu, bagaimana menganalisis dan mengoptimalkan fungsi masjid, bagaimana mentransformasi dan menemukan konsep program masjid terhadap aktivitas mahasiswa.

${ }^{4}$ Menurut data kearsipan masjid at-Taqwa. 


\section{Metode Penelitian}

1. Menganalisis fungsi masjid at-Taqwa Kemanggisan dan masjid-masjid kampus dari segi Ibadah, Pendidikan, Dakwah, Ekonomi, Sosial Kemasyarakatan, Politik, Kesehatan, Teknologi, Ukhuwah Islamiyah, dan Kaderisasi.

2. Optimalisasi fungsi Masjid at-Taqwa Kemanggisan dan beberapa masjid kampus.

3. Transformasi program masjid terhadap aktivitas mahasiswa.

4. Menemukan konsep program masjid yang relevan dengan aktivitas mahasiswa.

Bagi Peniliti, hasil penelitian ini dimaksudkan memberikan kontribusi terhadap perkembangan dan riset kemasjidan di Indonesia, khusunya mengenai kemahasiswaan. Hasil temuan konsep optimalisasi fungsi masjid saat ini dapat dijadikan rujukan bagi peneliti selanjutnya, dan akan lebih baik apabila para peneliti berikutya lain menggunakan metode dan tinjaun lain. Misalnya dari sisi karakter, psikologi, dan kecerdasan spiritual mahasiswa.

Bagi Pengelola, temuan konsep optimalisasi ini akan lebih bermanfaat bagi seluruh pengelola masjid dalam mengakatifkan generasi muda khususnya mahasiswa. Konsep optimalisasi ini akan menghasilkan transformasi manajemen masjid yang lebih baik.

Bagi Masyarakat, kehadiran masjid akan lebih dirasakan oleh masyarakat dengan adanya pengimplementasian konsep optimalisasi fungsi masjid ini sehingga diharapkan masyarakat berpartisipasi aktif.

Menurut alur pemikiran peneliti, proses penentuan kerangka konseptual penelitian dimulai dengan penjelasan dasarnya terlebih dahulu (philosophical thinking), yaitu pemahaman tentang fungsi masjid yang seharusnya di jalankan dengan mengacu kepada masjid masa awal periode Islam. Selanjutnya melakukan analisis data, menentukan rumusan optimalisasi, mengadakan transformasi dan penemuan konsep program masjid yang relevan dengan aktivitas mahasiswa (Gambar II-1). 


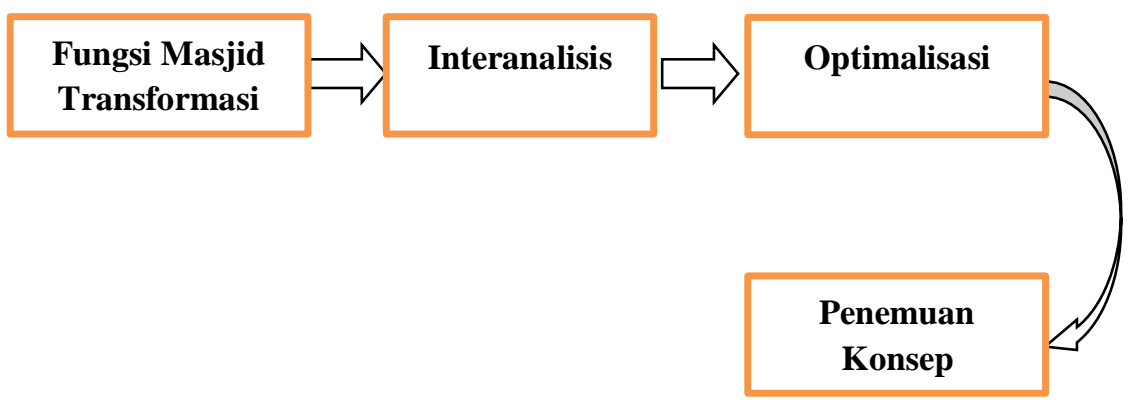

Penelitian ini menggunakan metode kualitatif, dengan fokus yang diarahkan pada realitas sosial yang berubah dan sebagai hasil konstruksi sosial yang berlangsung antara pelaku dan institusi sosial. Metode kualitatif juga diarahkan pada latar konteks dan individu secara holistik, dan karenanya individu atau organisasi tidak diisolasi ke dalam variable atau hipotesis, namun perlu untuk memandangnya sebagai bagian dari suatu kekuatan. ${ }^{5}$ Penelitian kualitatif ini mengangkat sebuah fenomena yang terjadi dalam ruang lingkup masjid. Penelitian kualitatif merupakan penelitian yang menggunakan pendekatan naturalistik untuk menemukan pemahaman mengenai fenomena dalam suatu latar yang berkonteks khusus. Penelitian kualitatif adalah penelitian yang terjadi pada lingkup sosial yang mencakup pelaku, kejadian, tempat, dan waktu. Keempat cakupan tersebut dinamakan social setting. ${ }^{6}$

Ada beberapa pendekatan yang menjadi landasan pemahaman terhadap gejala sosial yang terdapat dalam masyarakat, menurut peta tradisi teori ilmu sosial. Salah satu dari pendekatan yang terdapat dalam ilmu sosial itu adalah fenomenologi. Fenomenologi secara umum dikenal sebagai pendekatan yang dipergunakan untuk membantu memahami berbagai gejala atau fenomena sosial dalam masyarakat. Peranan fenomenologi menjadi lebih penting ketika tempat obsevasi dari metode penelitian sosial dalam pengamatan terhadap pola perilaku seseorang sebagai aktor sosial dalam masyarakat. Implikasi secara

\footnotetext{
${ }^{5}$ Bogdan dan Taylor sebagaimana dikutip Lexi J. Moleung, Metode Penelitian Kualitatif, Bandung: Remaja Karya, 1989, hal. 3.

${ }^{6}$ L.J, Moleong, Metodologi Penelitian Kualitatif, Edisi Revisi, Bandung : PT Remaja Rosdakarya, 2005, hal. 5.
} 
teknis dan praktis dalam melakukan pengamatan aktor bukanlah esensi utama dari kajian fenomenologi sebagai perspektif. Fenomenologi lebih merupakan tawaran cara pandang baru terhadap fokus kajian penelitian dan penggalian makna yang terbangun dari realitas kehidupan sehari-hari di dalam penelitian secara khusus dan dalam kerangka luas pengembangan ilmu sosial. ${ }^{7}$

Objek penelitian peneliti adalah masjid yang strategis karena masjid yang dekat dengan beberapa kampus. Peneliti telah meneliti Masjid at-Taqwa Kompleks Pajak Kemanggisan Jakarta Barat yang terletak di Perumahan Pajak yang dikelilingi Perumahan BI, Perumahan MIGAS dan Perumahan PLN. Penelitian selanjutnya adalah Masjid Kampus Universitas Trisakti, Masjid Kampus Universitas Tarumanagara, Masjid Kampus Esa Unggul, Masjid Kampus dan Majlis Ta'lim al-Khawarizmi Universitas Bina Nusantara, dan Masjid Kampus Mercu Buana.

Data dalam penelitian ini berupa keterangan, informasi tentang bidang yang sedang diamati dalam bentuk kata-kata (teks), foto, cerita, gambar, artifak yang diperoleh secara langsung dari partisipan maupun dari orang lain. Data penelitian dapat dibedakan berdasarkan sumber informasi darimana diperoleh serta jenis data dengan cara bagaimana informasi tersebut didapatkan.

Klasifikasi data dalam perspektif sumber informasi dibedakan antara data primer (utama) dengan data sekunder (tambahan). Data utama penelitian kualitatif yakni data yang pertama kali dicatat dan dikumpulkan oleh peneliti, sedangkan data sekunder adalah data yang sudah tersedia dan dikumpulkan oleh pihak lain. Bentuk data utama penelitian kualitatif yakni kata-kata dan tindakan subyek (responden), selain data tersebuta adalah data tambahan yang dapat diperoleh dari catatan harian, fotograf, dokumen resmi, serta artikel surat kabar, bulletin, dan majalah. ${ }^{8}$

Teknik pengumpulan data merupakan langkah yang paling strategis dalam penelitian karena tujuan utama dari penelitian adalah mendapatkan data. Teknik pengumpulan

${ }^{7}$ Alferd Schutz, "Phenomenology and Research Methodology for Information Behavior Research," dalam: www. informationr/ net/ tdw/ publ/ papers/schutz02.html. Diakses pada tanggal 23 Maret 2010.

${ }^{8}$ Anwar Sanusi, Metodologi Penelitian Praktis Untuk Ilmu Sosial dan Ekonomi, Malang: Buntara Media, 2003, hal. 88. 
data sangat diperlukan dalam suatu penelitian karena hal tersebut digunakan penulis untuk mendapatkan data yang akan di analisis sehingga bisa ditarik kesimpulan. Terdapat bermacam teknik pengumpulan data yang biasa dipakai dalam melakukan penelitian.

Berikut adalah teknik pengumpuan data yang digunakan penulis dalam penelitian ini adalah:

1. Studi Pustaka

Salah satu studi pustaka adalah teknik simak. Yang termasuk teknik simak adalah teknik catat. Teknik catat merupakan teknik pengumpulan data dengan cara menggunakan buku-buku, literatur ataupun bahan pustaka, kemudian mencatat atau mengutip pendapat para ahli yang ada di dalam buku tersebut untuk memperkuat landasan teori dalam penelitian. Teknik catat ini menggunakan buku-buku, literatur, dan bahan pustaka yang relevan dengan penelitian yang dilakukan, biasanya dapat ditemukan di perpustakaan maupun di tempat penulis melakukan penelitian. ${ }^{9}$ Pada penelitian ini, peneliti mengumpulkan data-data dari buku, laporan, proposal, hasil penelitian dan beberapa website serta artikel-artikel yang berkaitan dengan organisasi kemasjidan.

2. Observasi

Dari observasi diperoleh tempat, pelaku kegiatan, kejadian atau peristiwa dan waktu. Observasi dilakukan untuk menyajikan gambaran yang realistis perilaku atau kejadian. Kejadian tersebut untuk menjawab pertanyaan, dan membantu mengerti perilaku informan dan untuk evaluasi melakukan pengukuran terhadap aspek tertentu serta melakukan umpan balik terhadap pengukuran.

3. Wawancara

Wawancara yang digunakan dalam metodologi fenomenologi mengunakan wawancara semi bestruktur yang berusaha seminimal mungkin mempengaruhi dan mengarahkan informan ini dalam menjawab. Dengan mengunakan wawancara yang seperti ini diharapkan peneliti mampu

\footnotetext{
${ }^{9}$ Mohammad Nasih, "Metode Pengumpulan Data," dalam http://eprints.undip.ac.id/40985/3/BAB_III.pdf . Diakses pada 26 November 2018.
} 
menangkap pengalaman dan pengetahuan informan secara lebih utuh dibandingkan dengan mengunakan wawancara yang sifatnya lebih formal atau kaku. Dengan begitu informan juga akan lebih bebas dalam mengekpresikan pengalamannya atau pengetahuannya. Sewaktu pembicaraan berjalan, orang yang diwawancarai diusahakan tidak mengetahui atau tidak menyadari bahwa ia sedang diwawancarai. ${ }^{10}$

4. Dokumentasi

Dokumentasi disini merupakan teknik pengumpulan data dengan cara mencatat kejadian yang ada dilapangan dengan memanfaatkan data sekunder yang ada. Data atau dokumentasi tersebut sebagai tambahan atau pelengkap dari penggunan metode observasi dan wawancara dalam penelitian kualitatif. Dokumen dalam penelitian ini berbentuk gambar, foto, table, maupun grafik.

Analisis data yaitu kegiatan analisis mengategorikan data untuk mendapatkan hubungan, tema, menaksir apa yang bermakna, dan menyampaikan atau melaporkannya kepada orang lain yang berminat. ${ }^{11}$ Dalam menganalisis data terdiri dari tiga langkah yaitu reduksi data, penyajian, dan penarikan simpulan. ${ }^{12}$ Pertama setelah data selesai dikumpulkan, data direduksi yaitu menggolongkan, mengarahkan dan membuang data yang tidak perlu; kedua data disajakan dalam bentuk teks naratif atau matriks; ketiga mengambil kesimpulan berdasarkan data yang telah dipaparkan dengan menggunakan pola pikir induktif.

Dalam penelitian ini peneliti menggunakan modifikasi teknis analisis data fenomenologi ${ }^{13}$. Rangkaian proseduralnya adalah sebagai berikut:

1) Membuat daftar dan pengelompokan awal data yang diperoleh. Pada tahap ini dibuat daftar pertanyaan

${ }^{10}$ L.J, Moleong, Metodologi Penelitian Kualitatif, Edisi Revisi, Bandung : PT Remaja Rosdakarya, 2005, hal. 187.

${ }^{11}$ Husaini Usman dan Purnomo, Metodologi Penelitian Sosial, Jakarta: PT Bumi Aksara, 2008, hal. 84.

12 Miles, B. Mathew dan Michael Huberman. 1992. Analisis Data Kualitatif Buku Sumber Tentang Metode-metode Baru. Jakarta: UIP, hal. 8

${ }^{13}$ Clark Moustakas, Phenomenological Research Methods. California: SAGE Publications, 1994, hal. 121. 
berikut jawaban yang relevan dengan permasalahan yang diteliti (horizontalization).

2) Reduksi dan eliminasi.

3) Pada tahap ini kegiatan yang dilakukan adalah menguji data untuk menghasilkan invariant constitutes. $^{14}$

4) Mengelompokkan dan memberi tema setiap kelompok invariant constitutes yang tersisa dari proses eliminasi.

5) Identifikasi final terhadap data yang diperoleh melalui proses validasi awal data.

6) Mengkonstruksi definisi tekstual masing-masing informan, termasuk pernyataan-pernyataan verbal dari informan yang

7) berguna bagi penelitian selanjutnya.

8) Membuat deskripsi struktural, yakni penggabungan deskripsi tekstual dengan variasi imajinasi.

9) Menggabungkan langkah nomor lima dan enam untuk menghasilkan makna dan esensi dari permasalahan penelitian.

\section{Hasil dan Pembahasan}

Hasil Pembahasan berdasarkan analisis data, fungsi masjid, optimalisasi, dan temuan konsep program, sebagai berikut:

\begin{tabular}{|c|c|}
\hline $\begin{array}{c}\text { Kode Fungsi } \\
\text { Masjid }\end{array}$ & Nama Bidang Aktivitas \\
\hline 1 & Ibadah \\
\hline 2 & Pendidikan \\
\hline 3 & Dakwah \\
\hline 4 & Ekonomi \\
\hline 5 & Sosial Kemasyarakatan \\
\hline 6 & Politik \\
\hline 7 & Kesehatan \\
\hline 8 & Teknologi \\
\hline
\end{tabular}

${ }^{14}$ Invariant constituents, which are the horizons defined as the "core. themes of the experience" of the phenomenon, Moustakas: 1994, hal. 121. 
Optimalisasi Fungsi Masjid Untuk.. I

\begin{tabular}{|c|c|}
\hline $\begin{array}{c}\text { Kode Fungsi } \\
\text { Masjid }\end{array}$ & Nama Bidang Aktivitas \\
\hline 9 & Ukhuwah Islamiyah \\
\hline 10 & Kaderisasi \\
\hline
\end{tabular}

\begin{tabular}{|c|l|c|l|}
\hline No & $\begin{array}{c}\text { Tempat } \\
\text { Penelitian }\end{array}$ & $\begin{array}{c}\text { Fungsi Masjid yang } \\
\text { Mengalami Proses } \\
\text { Optimalisasi }\end{array}$ & $\begin{array}{l}\text { Temuan Konsep } \\
\text { Program }\end{array}$ \\
\hline 1 & $\begin{array}{l}\text { Masjid } \\
\text { at-Taqwa }\end{array}$ & $\begin{array}{c}1,2,3,4,5, \\
6,7, \text { dan } 8\end{array}$ & $\begin{array}{l}\text { Seleksi dan } \\
\text { keterlibatan } \\
\text { Mahasiswa dalam } \\
\text { Kepengurusan } \\
\text { Mahasiswa Untuk } \\
\text { Keaktifan di Masjid }\end{array}$ \\
\hline 2 & $\begin{array}{l}\text { Masjid } \\
\text { asy-Syuhada }\end{array}$ & $2,4,6$ dan 8 & $\begin{array}{l}\text { Memperbanyak } \\
\text { Mahasiswa dalam } \\
\text { Kepengurusan } \\
\text { ROHIS }\end{array}$ \\
\hline 3 & $\begin{array}{l}\text { Masjid } \\
\text { at-Taufik }\end{array}$ & $2,4,5$ dan 8 & $\begin{array}{l}\text { Mendatangkan Nara } \\
\text { Sumber dari luar } \\
\text { untuk Pengetahuan } \\
\text { Agama }\end{array}$ \\
\hline 4 & $\begin{array}{l}\text { Masjid } \\
\text { Baitul Gafur }\end{array}$ & $1,2,4,5$, dan 8 & $\begin{array}{l}\text { Presentasi kepada } \\
\text { mahasiswa baru } \\
\text { tentang pentingnya } \\
\text { aktif keagamaan }\end{array}$ \\
\hline 5 & $\begin{array}{l}\text { Majlis Taklim } \\
\text { Al- } \\
\text { Khawarizmi }\end{array}$ & $2,3,4$, dan 8 & $\begin{array}{l}\text { Pengadaan Tempat } \\
\text { Ibadah di Kampus }\end{array}$ \\
\hline 6 & $\begin{array}{l}\text { Masjid } \\
\text { 'Amarul }\end{array}$ & $6,7,8,9,10$ & $\begin{array}{l}\text { Penyatuan Misi dan } \\
\text { Misi Rohis antar } \\
\text { Jurusan }\end{array}$ \\
\hline
\end{tabular}

\section{Kesimpulan}

Konsep Optimalisasi dalam hal ibadah adalah mengadakan pelatihan shalat khusyu' agar menumbuhkan kecintaan dalam shalat, melakukan shalat dengan tidak 
terburu-buru, memahami bacaan shalat. dan undangan untuk melaksanakan shalat jama'ah di masjid misalkan terutama shalat shubuh berjama'ah. Dalam bidang pendidikan diusulkan pendalaman materi keilmuan secara spesifik, penanaman iman dan karakter Islam pada mahasiswa. Pemuda merupakan generasi masa depan yang harus dipersiapkan dan dijaga ilmu, iman dan akhlaknya. Maka dari itu, pendidikan ilmu, iman dan akhlak yang dijalankan di masjid sebaiknya dikhususkan lebih banyak kepada pemuda khususnya mahasiswa.

Proses transformasi telah menjadi channel of change sekaligus agency of change bagi masyarakat kampus. Peran-peran mereka dijabarkan dengan aktivitas melalui program-program masjid yang dapat membentuk karakter keshalihan individu yang berimbas terhadap keshalihan sosial. Salah satu indikator keberhasilan proses transformasi adalah berupa kemandirian, kerjasama dan fasilitatif dari pihak lain. Transformasi harus bisa mengembalikan fungsi dasar keberadaan masjid, yakni penyeimbangan antara fungsi ritual dan fungsi sosial.

\section{Daftar Pustaka}

Ali, M. Daud. Pendidikan Agama Islam, Jakarta: PT Raja Grafindo, 1998.

Ali Ash-shalabi, Muhammad. 2012. Sejarah Lengkap Rasulullah SAW Fikih dan Studi Analisa Komprehensif. Jakarta: Pustaka Al-Kausar, 2012.

Al-Mubarakfury, Shafiyyurrahman. Sirah Nabawiyah, Jakarta: Pustaka Al-Kautsar, 2006.

Arifin, M. Ilmu Pendidikan Islam, Jakarta: Bumi Aksara, 2008.

Arni, Muhammad. Komunikasi Organisasi, Jakarta: Bumi Aksara, 2004.

Astari, Puji. Mengembalikan Fungsi Masjid sebagai Pusat Peradaban Masyarakat, IAIN Raden Intan Lampung: Jurnal Ilmu Da'wah dan Pengembangan Komunitas, 2014.

Auliyah, Robiatul. Studi Fenomenolgi Peranan Manajemen Masjid at-Taqwa dalam Pemberdayaan 
Ekonomi Masyarakat Bangkalan." Tesis. Madura: Universitas Trinujoyo Madura, 2015.

Badan Penelitian Dan Pengembangan, Pengembangan Pendidikan Budaya dan Karakter Bangsa, Kementrian Pendidikan Nasional Badan Penelitian dan Pengembangan Pusat Kurikulum, Jakarta: 2000.

Basir, Abdul. Lembaga pendidikan Masjid Periode Klasik (Telaah Atas Fungsi-Fungsi Masjid), Yogyakarta: Jurnal Darussalam, Vol. 7, No. 2 Juli 2008.

Berger, Peter L dan Thomas Luckman. Social Construction of Reality: A treatise in the Sociology of Knowledge, New York: Double Day \& Company, Inc, 1996.

Bogdan dan Taylor sebagaimana dikutip Lexi J. Moleung, Metode Penelitian Kualitatif, Bandung: Remaja Karya, 1989.

Bordieu, Pierre. Essay Towards A Reflexive Sociology, Cambridge: Blackwell, 1990.

Burde, Dana, dkk. Islamic studies as early childhood education in countries affected by conflict: The role of mosque schools in remote Afghan villages, Afghanistan: Jurnal Internasional, 2015.

Campbell, Tom. Tujuh Teori Sosial: Sketsa, Penilaian, dan Perbandingan, Yogyakarta: Penerbit Kanisius, 1994.

Cangara, Hafied. Perencanaan dan Strategi Komunikasi, Jakarta: Rajawali Pers, 2013.

Cecep, Sudirman Anshori. Ukhuwah Islamiyah Sebagai Fondasi Terwujudnya Organisasi yang Mandiri dan Profesional, Jurnal Pendidikan Agama Islam Ta'lim Vol. 14 No. 1 - 2016.

Chalil, Moenawar. Kelengkapan Tarikh Nabi Muhammad Shallallahu Alaihi Wasallam, Jakarta: Bulan Bintang, 1993.

Daradjat, Zakiyah. Ilmu Pendidikan Islam , Jakarta: Bumi Aksara, 2009.

Daymon, Christine dan Holloway, Immy. Riset Kualitatif, Terjemahan, Yogyakarta: PT Bentang Pustaka, 2001. 
Departemen Agama RI. "al-Qur'an dan Terjemahannya", Bandung: PT Sygma Examedia Arkanleema, tt.

Departemen Pendidikan dan Kebudayaan. Kamus Besar Bahasa Indonesia, Jakarta: Balai Pustaka, 1995.

E. Ayub, Mohammad. Manajemen Masjid, Jakarta: Gema Insani, 1996.

Edgar H. Schein. Organizational Culture and Leadership San Francisco: Jossey-Bass Publishers, Third Edition, 2004.

Fauzi Bin Abdurrahman, Muhd, dkk. Performance Measurement Model of Mosques I, Malaysia: Jurnal Internasional, 2015.

Fillah, Salim. Dalam Dekapan Ukhuwah, Yogyakarta: Pro-U Media, 2011.

Foster, Bellamy. Marx's Theory of Metabolic Rift: Classical Foundations for Environmental Sociology, Routledge: American Journal of Sociology, Vol. 105, No. 2 September 1999.

Friedrichs, Robert W. A Sociology of Sociology, New York: The Free Press, 1970.

Gazalba, Sidi. Masjid Pusat Ibadat dan Kebudayaan Islam, Jakarta: Pustaka Antara, 1971.

Geertz, Clifford. Penjaja dan Raja. Jakarta: LP3ES, 1977.

Gier, Nicholas F. Wittgenstein and Phenomenology: A Comparative Study of Later Wittgenstein, Husserl, Heidegger, and Marleau Ponty, New York: State University of New York University Press, 1981.

Hafidhuddin, Didin. Zakat Dalam Perekonomian Modern, Jakarta: Gema Insani, 2002

Hafidhuddin, Didin. Manajemen Syariah dalam praktek, Depok: Gema Insani, 2008

Haikal, H. Muhammad. Sejarah Hidup Muhammad, Jakarta: PT. Mitra Kerjaya Indonesia, 2005.

Yani, Ahmad. Panduan Memakmurkan Masjid, Jakarta : Gema Insani, 2009.

Yatim, Badri. Sejarah Peradaban Islam. Jakarta: Raja grafindo Persada, 2011.

Zahrah, M. Abu. Ushul Fiqih, Jakarta: Pustaka Firdaus, 2005. 
Optimalisasi Fungsi Masjid Untuk.. I

Zubaidi. Desain Pendidikan Karakter, Jakarta: Prenada Media, 2011.

Zuchdi. Humanisasi Pendidikan, Jakarta: PT. Bumi Aksara, 2009. 